\title{
A Wireless Strain Sensor Network for Structural Health Monitoring
}

\author{
Chengyin Liu, ${ }^{1,2}$ Jun Teng, ${ }^{2}$ and Ning $W^{2}$ \\ ${ }^{1}$ Key Laboratory of C\&PC Structures, Southeast University, Nanjing 211189, China \\ ${ }^{2}$ Department of Civil and Environmental Engineering, Harbin Institute of Technology, Shenzhen Graduate School, \\ Shenzhen 518055, China
}

Correspondence should be addressed to Chengyin Liu; chengyin.liu08@gmail.com

Received 7 August 2014; Accepted 15 January 2015

Academic Editor: Gangbing Song

Copyright (c) 2015 Chengyin Liu et al. This is an open access article distributed under the Creative Commons Attribution License, which permits unrestricted use, distribution, and reproduction in any medium, provided the original work is properly cited.

\begin{abstract}
Structural strain under external environmental loads is one of the main monitoring parameters in structural health monitoring or dynamic tests. This paper presents a wireless strain sensor network (WSSN) design for monitoring structural dynamic strain field. A precision strain sensor board is developed and integrated with the IRIS mote hardware/software platform for multichannel strain gauge signal conditioning and wireless monitoring. Measurement results confirm the sensor's functionality regarding its static and dynamic characterization. Furthermore, in order to verify the functionality of the designed wireless strain sensor for dynamic strain monitoring, a cluster-star network evaluation system is developed for strain modal testing on an experimental steel truss structure. Test results show very good agreement with the finite element (FE) simulations. This paper demonstrates the feasibility of the proposed WSSN for large structural dynamic strain monitoring.
\end{abstract}

\section{Introduction}

In order to improve the safety level of engineering structures, structural health monitoring (SHM) has become a popular research topic to determine the condition of the monitored structure and identify potential problems at an early stage [1]. The SHM system often offers an opportunity to reduce the cost for maintenance, repair, and retrofit throughout the lifetime of structure. Estimates of the health of structure can be realized through monitoring the physical behavior and environmental condition, for example, acceleration, strain, and temperature. Traditional SHM approaches collect measured responses from a centralized data acquisition and analysis system, but they suffer from problems like expensive sensor installation/wiring, signal degradation along lengthy cables, and data flooding.

With the rapid advancement in smart sensing technology and wireless communication technology, wireless sensor network (WSN) offers an alternative solution to SHM [2]. Compared to the traditional methods, the use of wireless technologies offers distinctive advantages in the field. For example, low-cost WSN instrumentation promises dense deployment of wireless sensors, which can increase the accuracy of the collected SHM data. Also, it promises fast and dense deployment and easier maintenance. Dense arrays of low-cost smart wireless sensor networks (WSNs) have the potential to improve the quality of the SHM dramatically using their on-board computational and wireless communication capabilities.

The Berkeley Mote smart sensor developed by Hill et al. [3] has emerged as an important new open hardware/software platform for SHM. The mote platform has a microprocessor and radio communication system. Users can easily customize both the hardware and software. Kurata et al. [4] have reported their experiences using the Mica mote wireless sensing platform for structural monitoring. Based on the Mica and Imote platforms [5], related work on using WSNs for structural monitoring includes notable experiments like Wisden, Tenet [6], and the Golden Gate Bridge deployment [7]. These WSNs provide rich information which SHM algorithms can utilize to detect, locate, and assess the structural damage caused by severe loading events and progressive 


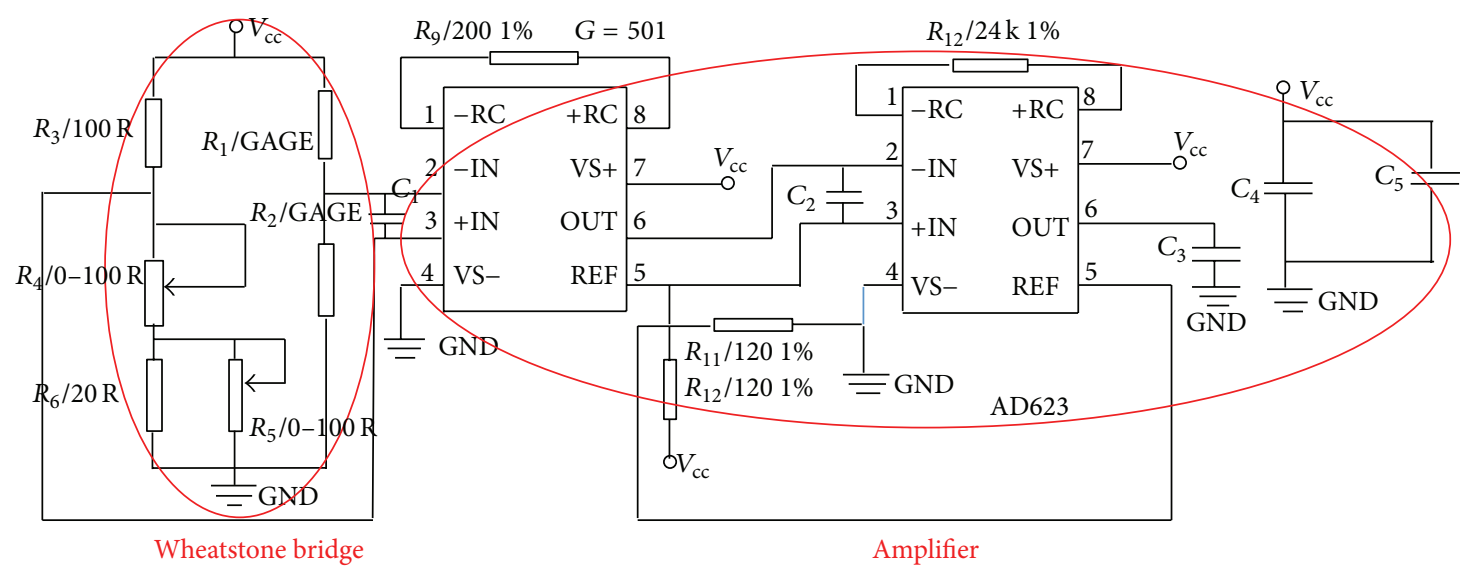

FIGURE 1: Wireless strain sensor board circuit schematic.

environmental deterioration as well as economical realization of the SHM system [8].

In recent years, several other WSN systems have been proposed for SHM. Lynch et al. [9] deployed 14 wireless sensors to monitor the forced acceleration responses of Geundang Bridge in Korea. However, their system is also of singlehop network type. Bocca et al. [10-12] introduced a timesynchronized WSN and a WSN with embedded Goertzel algorithm to process the acceleration data locally and in real time. In this work, the network is based on ISMO-2 nodes and organized into a star topology to enable accelerometer measurement on a wooden model bridge.

In addition to acceleration, strain is one of the most important physical quantities to judge the health of a structure [13]. As an effective sensing unit, the strain gauge has been applied to local monitoring for a long time [14]. For traditional strain collection and transmission systems, the strain collection device is big in volume, the circuit performance and collection precision is affected by the wire length, and the installation and maintenance cost can be very high. All these factors have limited the application of local sensing units. To find a good solution to extricate strain monitoring from this dilemma, in the past decade, magnetically soft sensors, self-diagnosis materials, and fiber optics sensing technology have been mostly deployed [1517]. In particular, the fiber Bragg grating sensors have been demonstrated to be capable obtaining precise amounts of strain of structures $[18,19]$. The utility of FBG sensors has been demonstrated in field applications, as well as in numerous laboratory tests. Meanwhile, research on structural local monitoring using wireless sensing technology is increasing. Whelan et al. [20] recently addressed the strainbased low-power monitoring problem with a WSN, and a customized data acquisition platform (called WSS) based on Tmote Sky Mote was proposed, which conducts strain-based monitoring through a switch. Gangone et al. [21] discussed the load testing and the rating of a simply supported bridge, in which WSS from strain measurements was deployed. This approach can provide complete information for SHM. However, large-scale communication issue in SHM could not be addressed because this system relies on single-hop, star topology wireless communication between sensors and base stations. Currently, most of the available sensor boards paired to the Berkeley Mote are not specially designed for strain field monitoring on large structures.

This paper aims to present a WSN-based strain monitoring system, and a customized wireless strain sensor board for multichannel strain gauge signal conditioning and monitoring is developed based on a commercially available IRIS mote platform. This system was developed with the objective of integration, miniaturization, high-reliability, and low cost. The WSSN is suitable for monitoring static and dynamic structural strain responses under random loads and is thus capable of continuous monitoring. A multihop, cluster-star network is developed and its performance is experimentally validated on a steel truss structure. The test results along with the FE simulations will be shown to prove the feasibility of the WSSN for large structural dynamic strain monitoring.

\section{Wireless Sensor for Dynamic Strain Monitoring}

A wireless strain sensor is composed of strain sensor board, IRIS mote, and strain gauges with the resistance of $120 \mathrm{ohm}$. Due to IRIS mote's scalable design, user can customize the hardware and software according to the application needs. In this paper, a new strain sensor board is developed, and the hardware and software integration with the IRIS mote will be addressed in the following paragraphs.

2.1. Strain Sensor Board Design. As shown in Figure 1, the strain board circuit is designed for the sensor input unit. The circuit is composed of three parts, the bridge circuit, the amplifier, and the output circuit. A quarter Wheatstone bridge circuit and two variable gain amplifiers are implemented to achieve a wide measurement range due to the IRIS's 10 bit ADC restriction.

A quarter Wheatstone bridge is designed with one working resistance stain gauge and another temperature 


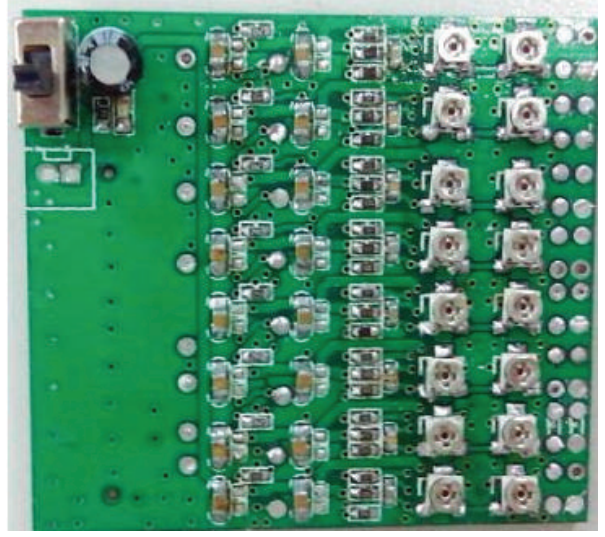

(a)

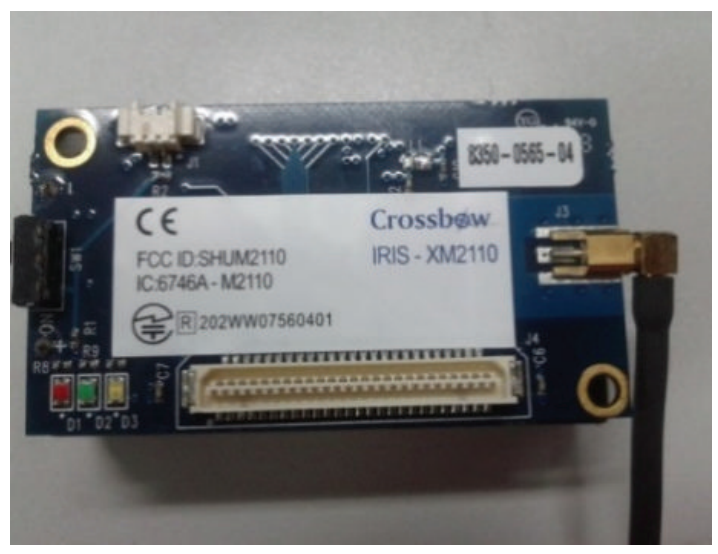

(b)

FIGURE 2: (a) Strain sensor board and (b) IRIS mote.

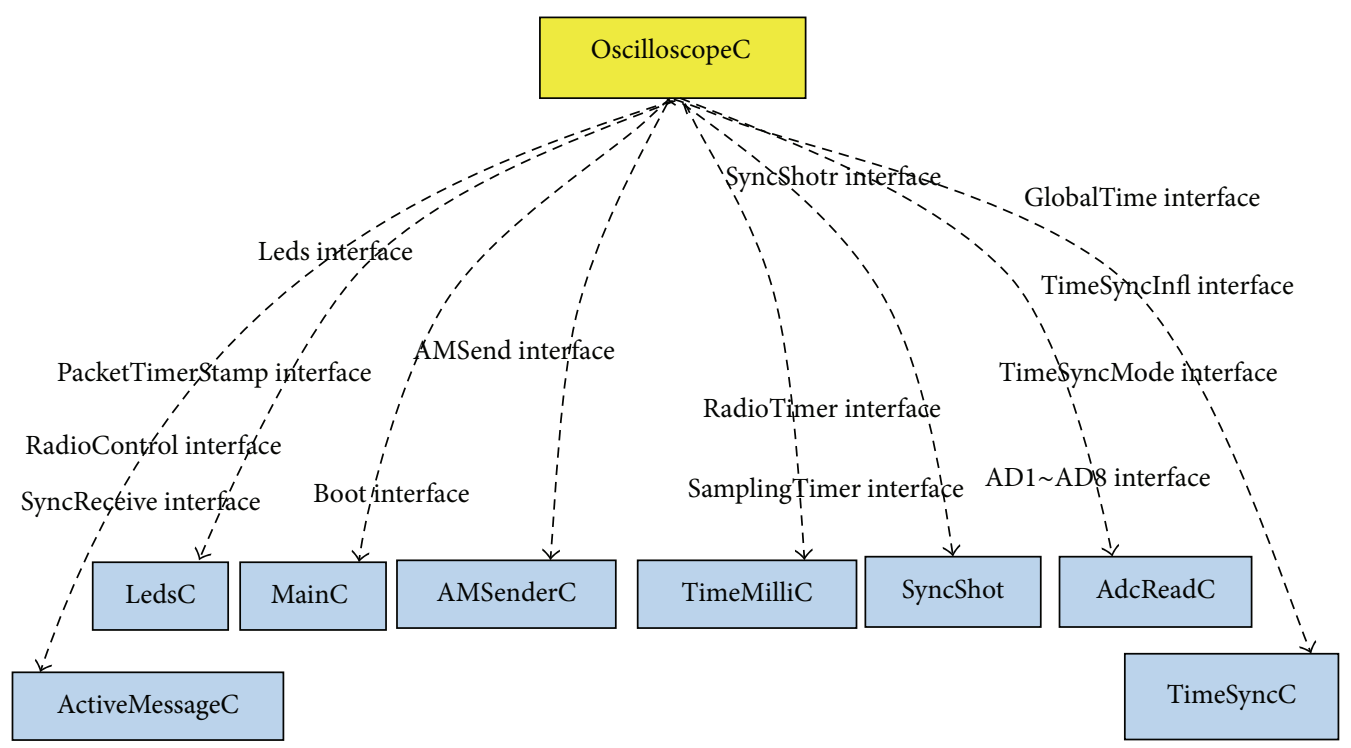

FIGURE 3: The application components for wireless strain sensor.

compensation resistance strain gauge. As the signal being amplified two times, the Wheatstone bridge should be absolute equilibrium otherwise the unbalanced errors can be amplified too. Therefore, a leveling circuit is designed in the Wheatstone bridge including coarse tuning and fine tuning. The coarse tuning is achieved by the adjustable resistance R4. The fine tuning is achieved by the resistance R6 and adjustable resistance $\mathrm{R} 5$ in parallel.

Two instrumentation amplifiers AD623 are adopted to magnify the bridge circuit output. As a low-power instrumentation amplifier, the AD623 can offer excellent accuracy for the sensor input unit of the wireless sensor nodes. A lowpass filter is designed to eliminate the high frequency noise. This filter also reduced the problem of aliasing. Note that the dynamic signal may be below 0; the strain sensor board is accordingly designed to make certain that the input signals are always above 0 to satisfy the sensor input voltage range requirement.
2.2. IRIS Mote Platform. The developed strain sensor board shown in Figure 2(a) is connected to IRIS mote platform through a 51-pin expansion connector. The IRIS mote as shown in Figure 2(b) and has an Intel Xscale processor and RAM of $256 \mathrm{~KB}$. The radio components are capable of transmitting data at transmission rate of $250 \mathrm{Kbps}$. The 51-pin expansion connector supports 8 channel analog inputs which can be used to acquire the analog signals. The hardware is appropriate for strain monitoring application. IRIS motes run on TinyOS [2] operating system platform that handles task scheduling, radio communication, time synchronization, and I/O processing, and so forth.

2.3. Software Design for Wireless Strain Sensor. To support the wireless strain sensor node hardware integration, an open source operating system, TinyOS, is utilized to program the IRIS. The application components used for wireless strain sensor integration are presented in Figure 3. Component 


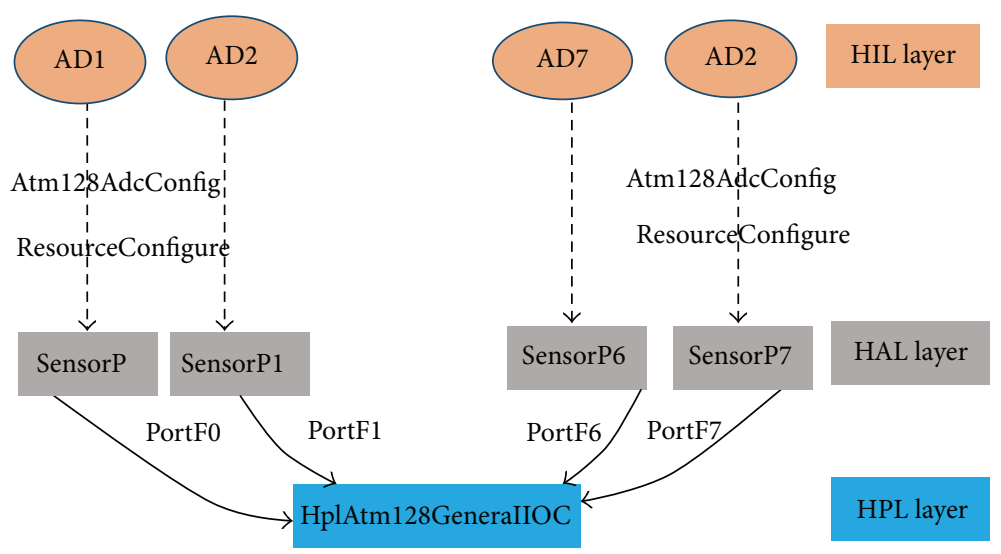

FIGURE 4: Pins driver program.

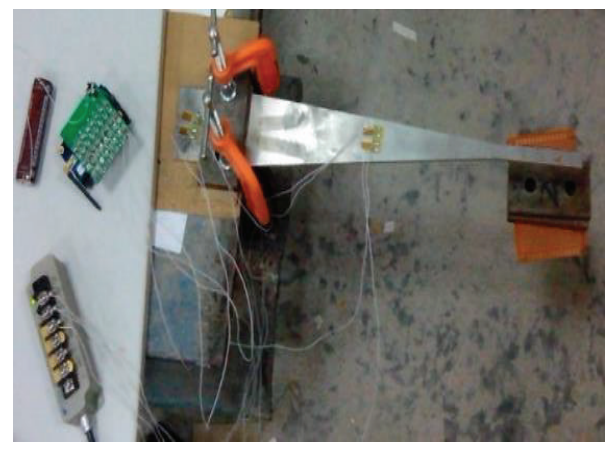

FIGURE 5: Static experiment setup.

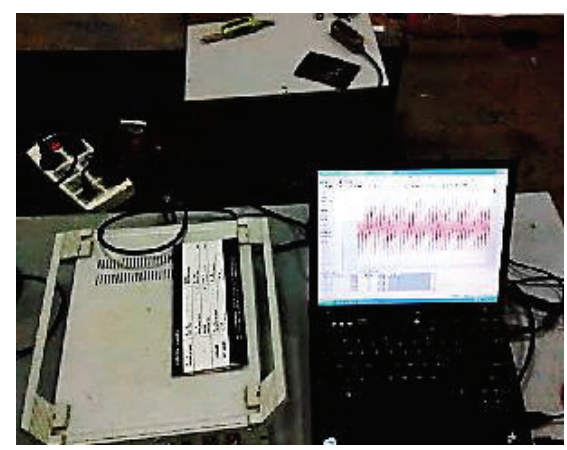

Figure 6: Data acquisition system.

AdcReadC is a driver module used to drive the AD channels. The 51-pin expansion connector of IRIS mote supports 8 channel analog inputs for collecting strain signals. Hence, only 8 channel analog pins need to be driven. Figure 4 shows the process of the developed driver module driving the IRIS mote from the hardware interface layer (HIL) to the hardware presentation layer (HPL) step by step. With the pins driver program we can control the $\mathrm{AD}$ channels for strain signals. Note that a triggering timer component is specially developed for periodic sampling of dynamic strain signals.

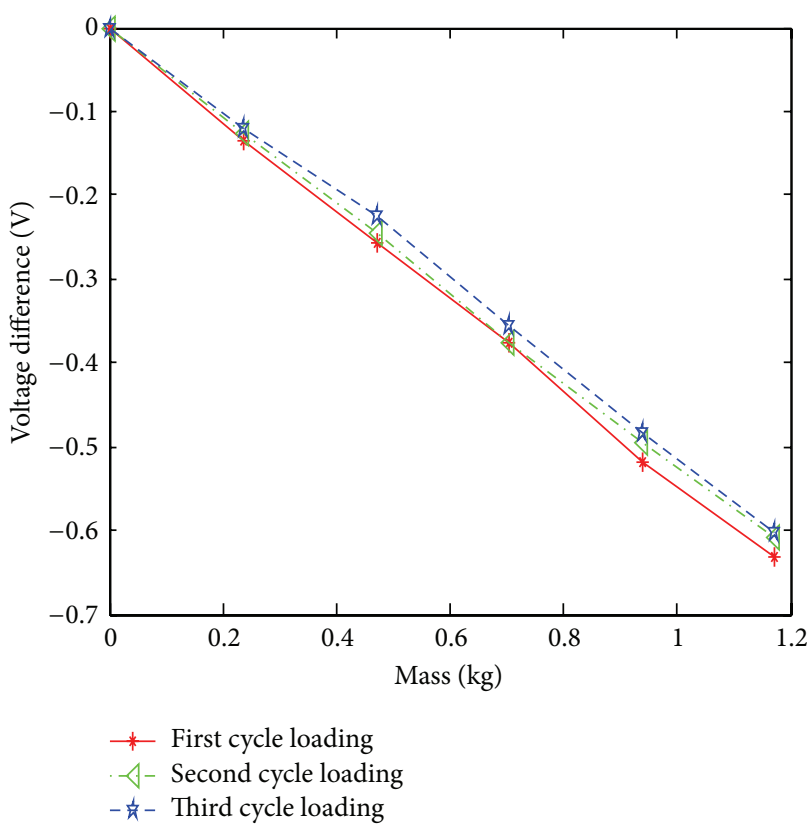

Figure 7: Three cycles loading.

\section{Wireless Strain Sensor Characterization}

After the fabrication of the sensor node, node characterization is performed in a laboratory environment. In this paper, the characterization for the sensor node is to investigate its static and dynamic performance of strain signal acquisition and sensitivity coefficient calibration.

3.1. Static Characterization. The first test is to investigate the linearity error and repeatability error of the strain sensor signal acquisition. Figure 5 shows the picture of the setup for the static characterization. 4 stain gauges are attached to the upper and lower surface of an equal intensity beam. DH5922 data acquisition system, as shown in Figure 6, is used to form measuring bridge. Table 1 lists the experimental data of the sensor input unit through repetitive loading to the equal intensity beam. The results are used to calculate 
TABLE 1: Loading and unloading of three cycles.

\begin{tabular}{|c|c|c|c|c|c|c|}
\hline \multirow{3}{*}{$\begin{array}{l}\text { Load }(\mathrm{kg}) \\
\text { Mass } \\
\Delta m\end{array}$} & \multicolumn{6}{|c|}{ Output (V) } \\
\hline & \multicolumn{2}{|c|}{ First cycle } & \multicolumn{2}{|c|}{ Second cycle } & \multicolumn{2}{|c|}{ Third cycle } \\
\hline & Loading & Unloading & Loading & Unloading & Loading & Unloading \\
\hline 0 & 2.1284 & 2.1143 & 2.1143 & 2.1267 & 2.1267 & 2.1274 \\
\hline 0.236 & 1.9946 & 1.9996 & 1.9874 & 1.9855 & 2.0074 & 2.0164 \\
\hline 0.472 & 1.8724 & 1.8784 & 1.8684 & 1.8806 & 1.9018 & 1.9108 \\
\hline 0.704 & 1.7535 & 1.7680 & 1.7385 & 1.7565 & 1.7723 & 1.7629 \\
\hline 0.938 & 1.6088 & 1.6361 & 1.6183 & 1.6264 & 1.6421 & 1.6418 \\
\hline 1.170 & 1.4970 & 1.4970 & 1.5065 & 1.5065 & 1.5247 & 1.5247 \\
\hline
\end{tabular}

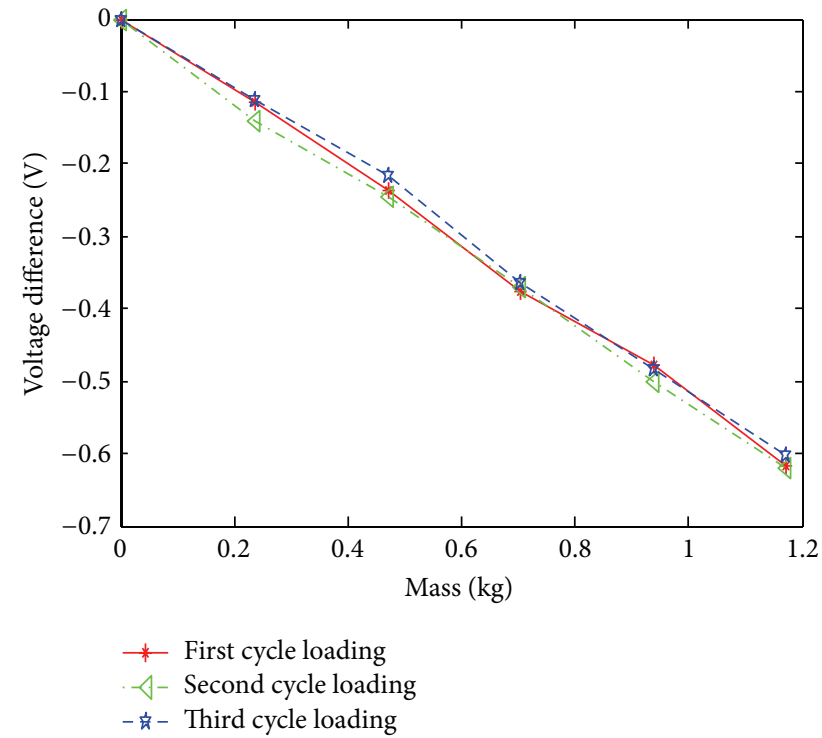

FIgURE 8: Three cycles unloading.

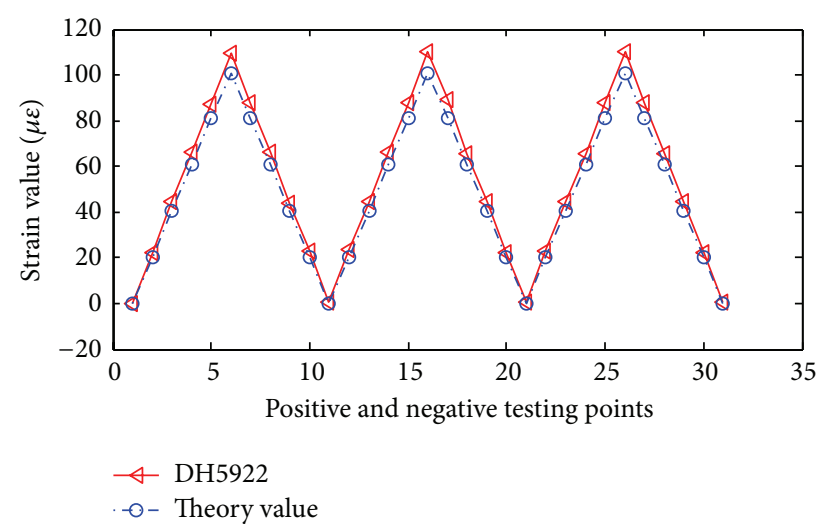

FIGURE 9: Strain data measured by DH5922 versus theoretic value.

the linearity error and repeatability error which are critical to the sensitivity coefficient calibration.

The values of mass $\Delta m$ and output voltage variation $\Delta U$ are summarized in Table 2. In Figures 7 and 8, the changes of output voltage variation $\Delta U$ are plotted versus mass variation $\Delta m$ for loading and unloading cases, respectively.

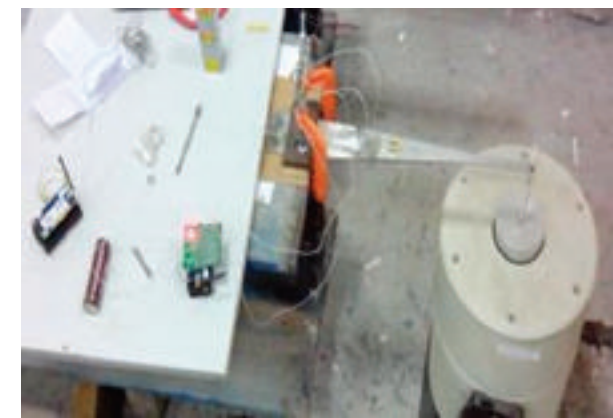

FIGURE 10: Vibration exciter.

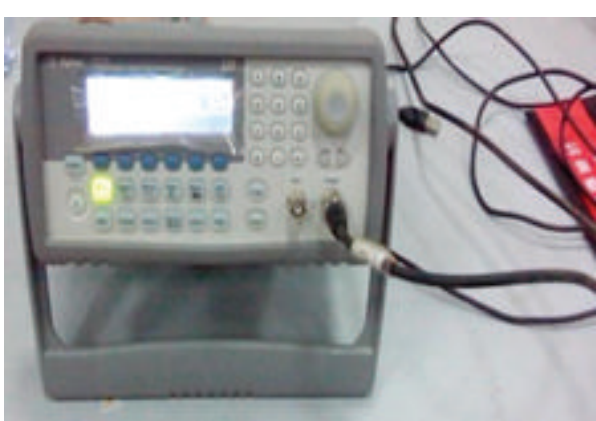

FIGURE 11: Signal Generator.

A linear approximation can be observed from Figure 7. In consequence, a linear fit equation is obtained in the following form:

$$
\Delta U=-0.5114 \times \Delta m-0.0124 .
$$

Table 3 lists the largest deviation $\Delta L_{\max }$ for output voltage variation $\Delta U$ obtained in testing. In Table 3, the largest deviation is found to be $\Delta L_{\max }=-0.0275$. Define the linearity error as

$$
\gamma_{L}= \pm \frac{\Delta L_{\max }}{y_{\mathrm{FS}}} \times 100 \%
$$

where $y_{\mathrm{FS}}$ is the full scale output. For the static characterization, the largest linearity error $\gamma_{L}=4.356 \%$ is acceptable for engineering application. 
TABLE 2: Relation of variation $\Delta m$ and variation $\Delta U$.

\begin{tabular}{lcccccr}
\hline $\begin{array}{l}\text { Load }(\mathrm{kg}) \\
\text { Mass }\end{array}$ & \multicolumn{2}{c}{ First cycle } & \multicolumn{2}{c}{ Voltage difference $(\mathrm{V})$} \\
\multicolumn{2}{c}{ Second cycle } & \multicolumn{2}{c}{ Third cycle } \\
$\Delta m$ & Loading & Unloading & Loading & Unloading & \multicolumn{2}{c}{ Loading } \\
\hline 0 & 0 & 0 & 0 & 0 & 0 & Unloading \\
0.236 & -0.1338 & -0.1147 & -0.1269 & -0.1412 & -0.1193 & -0.1110 \\
0.472 & -0.256 & -0.2359 & -0.2459 & -0.2461 & -0.2249 & -0.2166 \\
0.704 & -0.3749 & -0.375 & -0.3758 & -0.3702 & -0.3544 & -0.3645 \\
0.938 & -0.5196 & -0.4782 & -0.496 & -0.4997 & -0.4846 & -0.4822 \\
1.170 & -0.6314 & -0.6173 & -0.6078 & -0.6206 & -0.602 & -0.6027 \\
\hline
\end{tabular}

TABLE 3: The value of $\Delta L_{\max }$.

\begin{tabular}{|c|c|c|c|c|c|c|c|c|}
\hline \multirow{3}{*}{$\begin{array}{l}\text { Load (kg) } \\
\text { Mass } \\
\Delta m\end{array}$} & \multicolumn{8}{|c|}{ Voltage difference $(\mathrm{V})$} \\
\hline & \multicolumn{2}{|c|}{ First cycle } & \multicolumn{2}{|c|}{ Second cycle } & \multicolumn{2}{|c|}{ Third cycle } & \multirow{2}{*}{$\begin{array}{c}\text { Equation (1) } \\
\Delta U\end{array}$} & \multirow{2}{*}{$\begin{array}{c}\Delta L \\
\Delta L_{\max }\end{array}$} \\
\hline & Loading & Unloading & Loading & Unloading & Loading & Unloading & & \\
\hline 0 & 0 & 0 & 0 & 0 & 0 & 0 & -0.0124 & -0.0124 \\
\hline 0.236 & -0.1338 & -0.1147 & -0.1269 & -0.1412 & -0.1193 & -0.1110 & -0.1331 & -0.0221 \\
\hline 0.472 & -0.2560 & -0.2359 & -0.2459 & -0.2461 & -0.2249 & -0.2166 & -0.2438 & -0.0272 \\
\hline 0.704 & -0.3749 & -0.3750 & -0.3758 & -0.3702 & -0.3544 & -0.3645 & -0.3724 & -0.018 \\
\hline 0.938 & -0.5196 & -0.4782 & -0.4960 & -0.4997 & -0.4846 & -0.4822 & -0.4921 & -0.0275 \\
\hline 1.170 & -0.6314 & -0.6173 & -0.6078 & -0.6206 & -0.6020 & -0.6027 & -0.6107 & -0.0207 \\
\hline
\end{tabular}

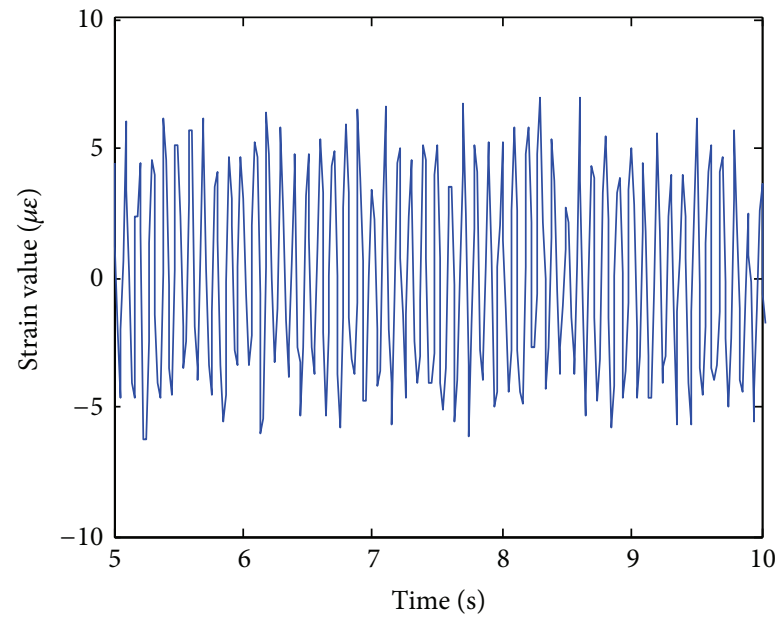

(a)

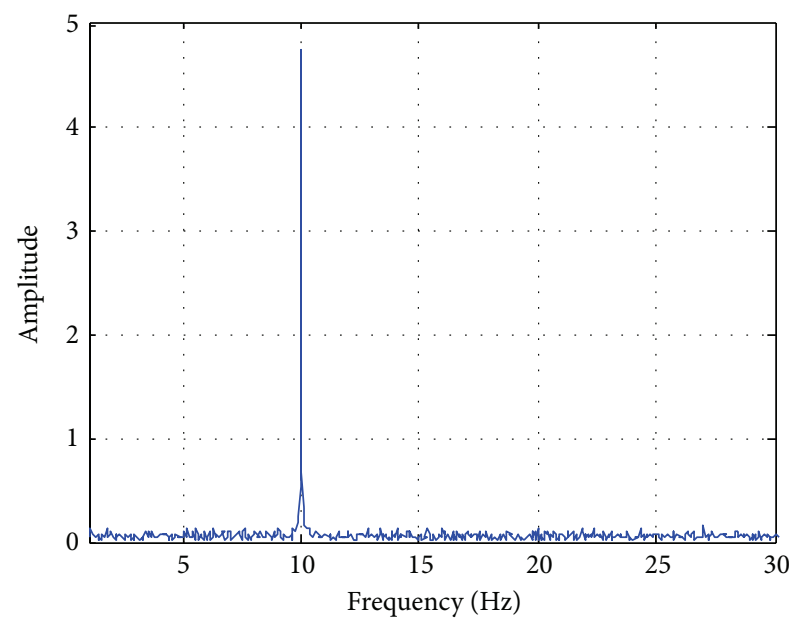

(b)

FIGURE 12: $10 \mathrm{~Hz}$ input wave: (a) strain signal and (b) frequency spectrum of the signal.

The linearity error is considered as a residual error in random distribution. Its standard deviation can be calculated as

$$
\delta=\sqrt{\frac{1}{n-1} \sum_{i=1}^{n}(\Delta L)^{2}}
$$

in which $n$ is the number of testing points and $\Delta L$ is the residual error. The repeatability error for the wireless strain sensor can be represented by $\gamma_{R}$ given by

$$
\gamma_{R}= \pm\left(\frac{3 \delta}{y_{\mathrm{FS}}}\right) \times 100 \% .
$$

Substituting the test data in Table 3 into formula (3) and formula (4), the standard deviation and repeatability error can be calculated as $\delta=0.01273$ and $\gamma_{R}=6.049 \%$. Experimental results show that the developed wireless strain sensor has a good static performance.

3.2. Sensitivity Coefficient Calibration. From Figure 9, we can see that the data measured by DH5922 is perfect compared to the theoretical value. The sensitivity coefficient of the DH5922 is set to 2 and the measuring bridge is the same with the wireless experiment when taking the experiments. Same as static performance tests, the relationship of mass variation 


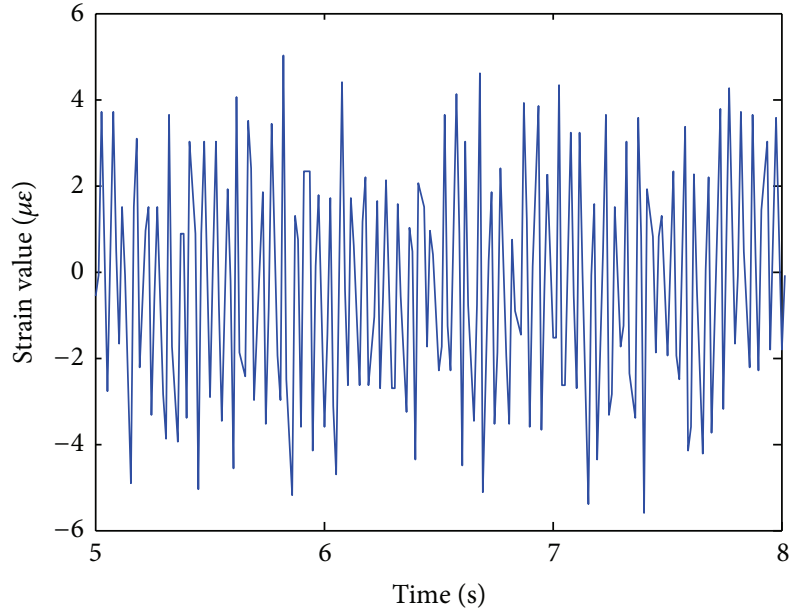

(a)

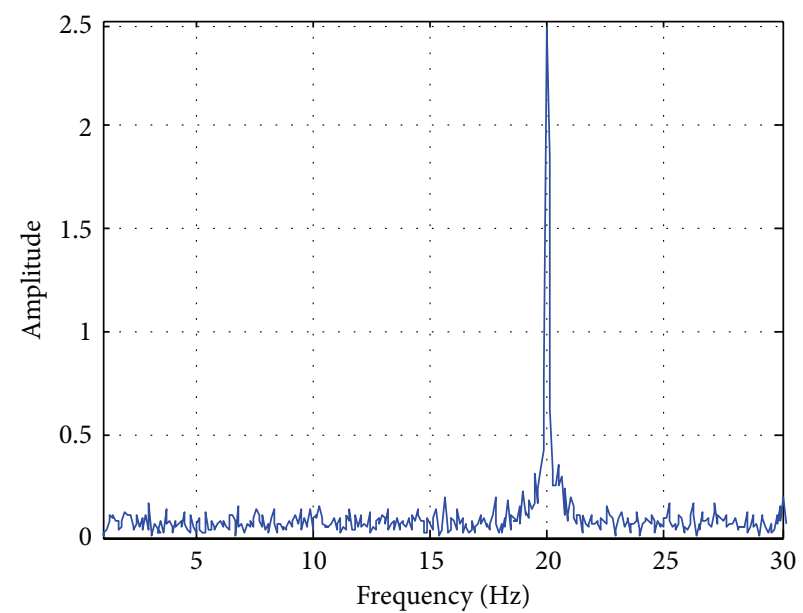

(b)

FIGURE 13: $20 \mathrm{~Hz}$ input wave: (a) strain signal and (b) frequency spectrum of the signal.

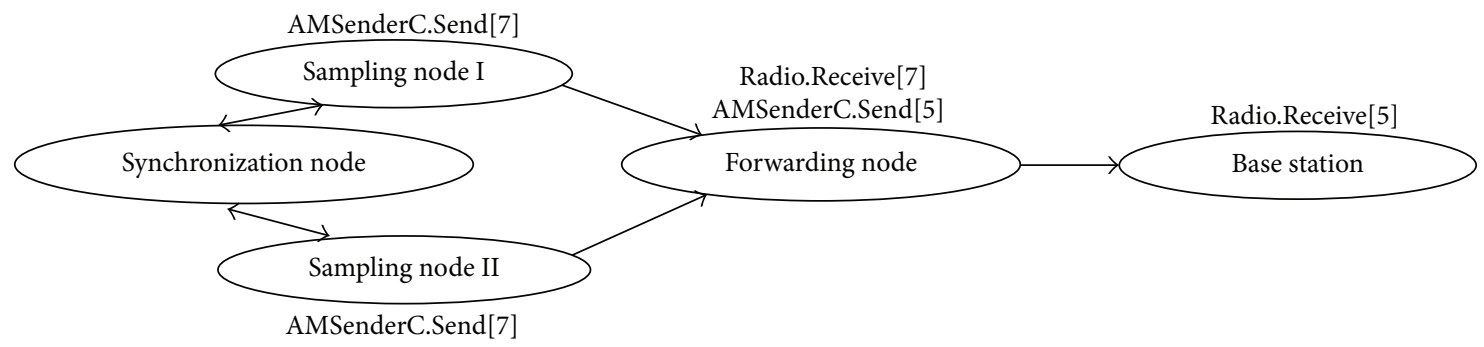

FIgURE 14: Workflow of data communication.

$\Delta m$ and strain variation $\Delta \varepsilon$ can be obtained with a linear fit, as shown if formula

$$
\Delta \varepsilon=93.7003 \times \Delta m+0.3233 .
$$

For a quarter Wheatstone-Bridge, we have

$$
\Delta \varepsilon=\frac{4 \Delta U}{U_{O} \times K_{S}}
$$

where $U_{O}$ is the value of power supply voltage and $K_{s}$ is the sensitivity coefficient which needs to be calculated.

Substituting (1) into (5) to eliminate the parameter $\Delta m$, we can get

$$
\Delta \varepsilon=-183.223 \Delta U+1.949 \text {. }
$$

Considering the amplification factors Gain1 and Gain2, thus (6) can be reformed as

$$
\frac{4}{U_{O} \times K_{S} \times \text { Gain } 1 \times \text { Gain } 2}=-183.223 \times 10^{-6},
$$

where the predefined amplification factors Gain1 and Gain2 are 501 and 5.16667 , respectively.

From (8), we can obtain the sensitivity coefficient for the wireless strain sensor $K_{s}=2.2195$.

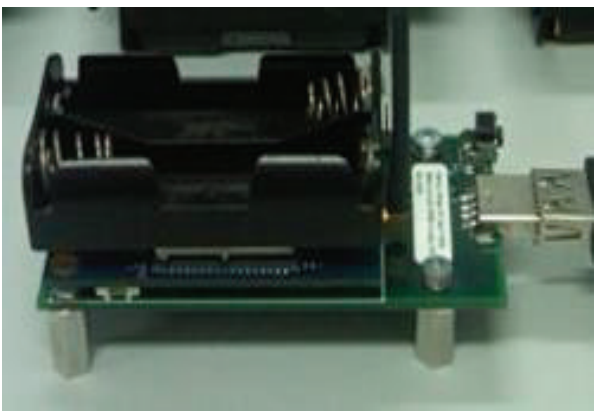

FIGURE 15: IRIS mote and MIB520.

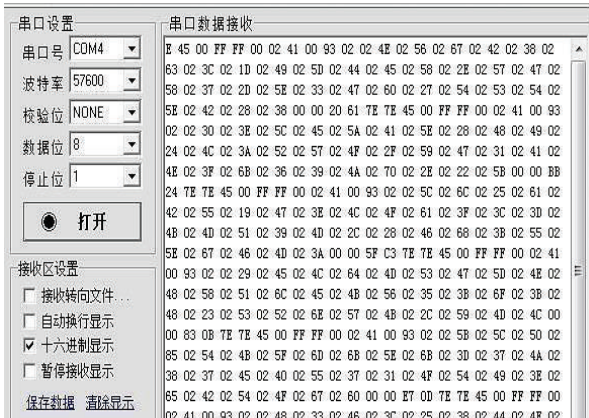

Figure 16: Interface of the serial software. 


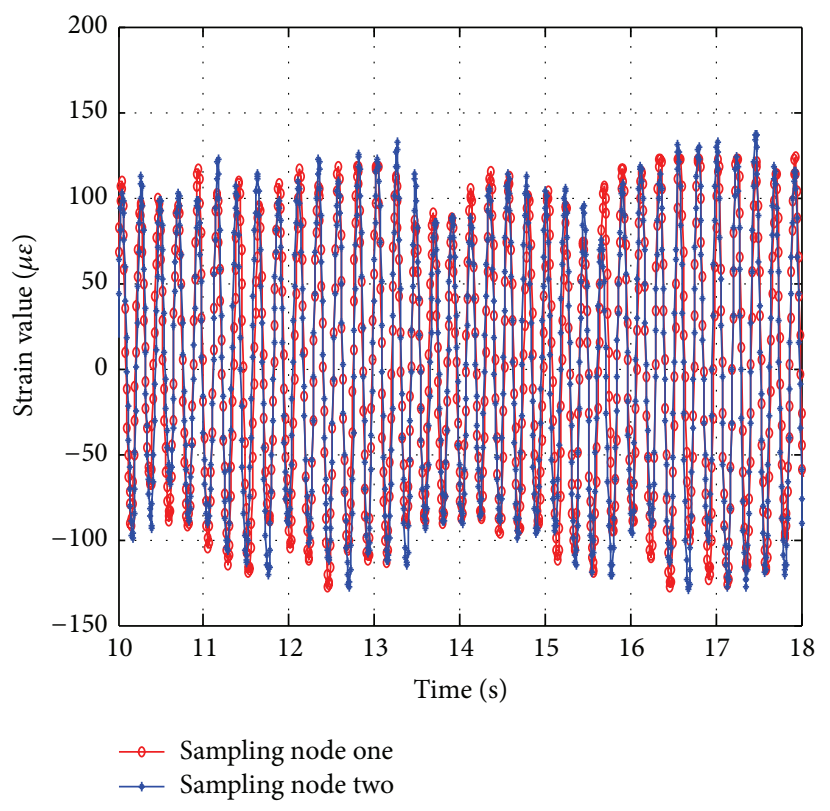

(a)

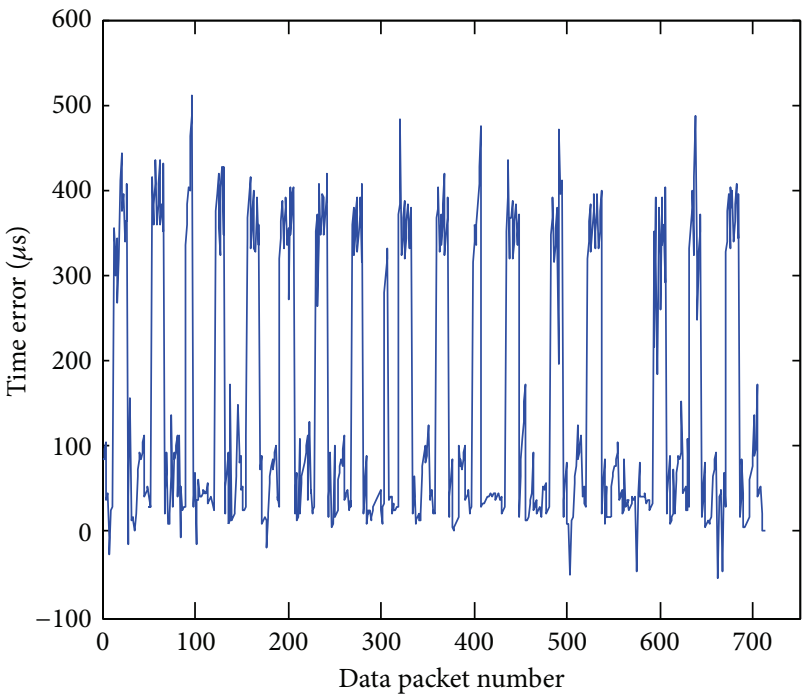

(b)

FIGURE 17: Time synchronization error of $128 \mathrm{~Hz}$ : (a) time history signal and (b) time error.

3.3. Dynamic Characterization. The response of the developed device to dynamic strain input is essential for determining the sensor's potential for monitoring the strains occurring during dynamic physical exercises such as walking or running. The objective is to find out to what extent the measurement channel's fill level is able to follow the periodic dynamic strain input without suffering from the loss of sensitivity.

For testing, a signal generator and a vibration exciter are added to the previous measurement setup as shown in Figures 10 and 11 . The signal generator sends wave commands to the vibration exciter, and, therefore, the cantilever beam is moved up and down by the vibration exciter with a specific frequency (signal generator controlled). Two input wave frequencies, $10 \mathrm{~Hz}$ and $20 \mathrm{~Hz}$, are chosen in this study for the characterization of the sensor devices, respectively.

The measurement results of the dynamic characterization of the strain sensor and frequency spectrum after Fourier transformation are shown in Figures 12 and 13. It can be observed that the target and actual frequencies are consistent at $10 \mathrm{~Hz}$ and $20 \mathrm{~Hz}$, respectively. Therefore, the potential for dynamic applications of the wireless strain sensor device can be expected.

\section{Wireless Strain Sensor Network Design}

In order to show the monitoring capability of the wireless sensor network, a two-tier wireless network is adopted to overcome time synchronization problems as well as the challenges in data transmission rates and power efficiency. The cluster head nodes communicating with the corresponding local leaf nodes form the bottom tier, and the base station communicating with the cluster head nodes forms the top tier. Accordingly, the middleware services developed on TinyOS for this application are thus including the signal acquisition module, the forwarding module, the base station module, and the time synchronization program embedded module. Figure 14 shows the workflow of data communication in the WSSN. By defining the components module active message (AM) type through TinyOS, the network route can be achieved. For example, the forwarding node can only receive signal from the node whose AMSenderC AM type is 7 and can only send signal to the node whose Radio.Receive AM type is 5 .

4.1. Sampling Module. In the signal acquisition module, known as leaf node, the AdcReadC component is developed to drive the analog ports. The component TimeMilliC is applied to control the sampling frequency of the sensor. TimesynC is used to synchronize sampling nodes and make sure that signals of the two nodes are synchronized. AMSenderC component is very important for WSSN data communication. It controls the receiving and transmitting signals between the determined nodes through predefining the node's active message (AM) type.

The forwarding module, also called the cluster head, is used to send the received signal from the sampling node to the computer through the base station. Similarly, this point to point data transmission is realized by predefining the AM type of the AMSenderC component.

Base station module functions as a bridge connecting WSSN and the computer. It sends instructions from computer to WSSN and transmits signals from WSSN to computer. The base station is composed of a programming board MIB520 and an IRIS node, as shown in Figure 15. It transmits data through a USB cable to the computer. Figure 16 shows 


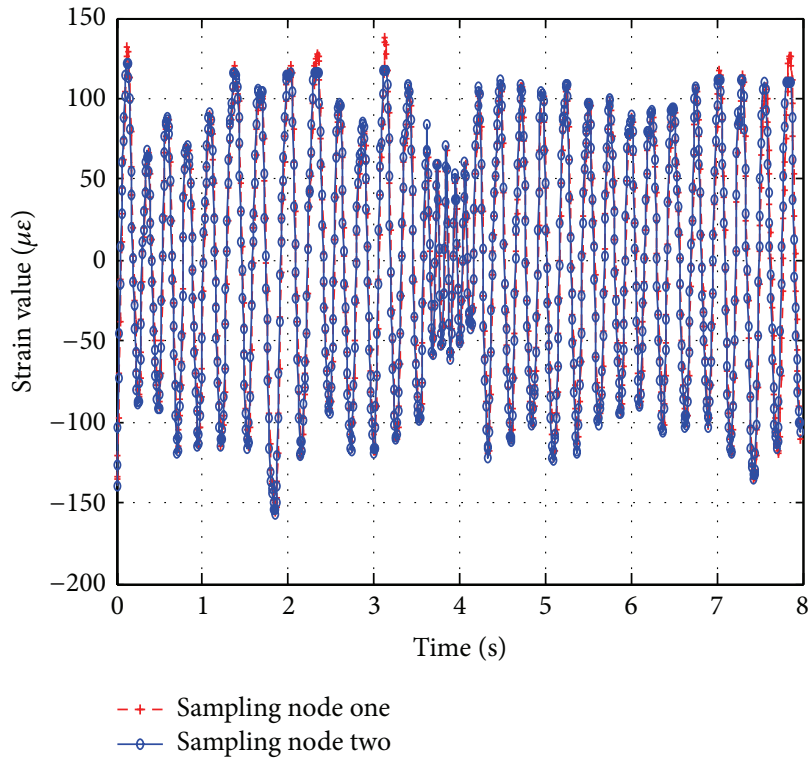

(a)

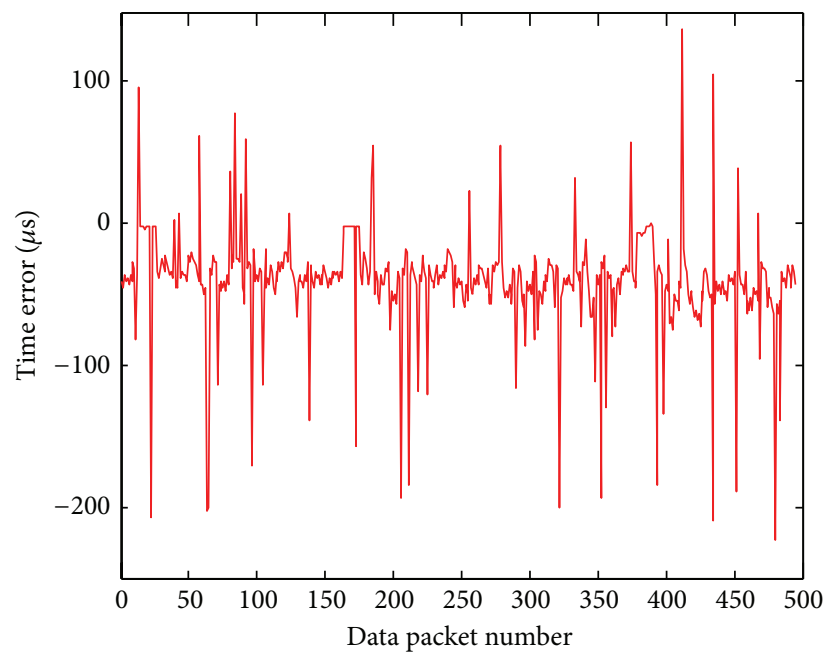

(b)

FIgURE 18: Time synchronization error of $64 \mathrm{~Hz}$ : (a) time history signal and (b) time error.

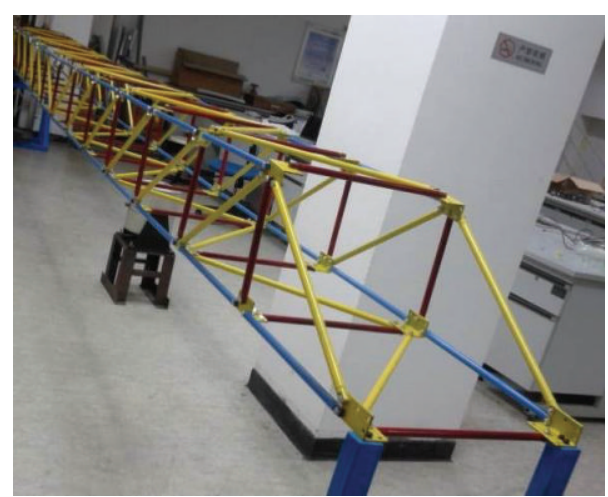

FIgURE 19: Test truss structure.

a sample of original data package collected from the computer interface. The original data is in hexadecimal format which needs to be converted to decimal notation before processing.

4.2. Time Synchronization Module. Time synchronization in a wireless sensor network is important for routing and power conservation. Time synchronization error in a smart sensor network can cause inaccuracy in SHM applications. Global time synchronization allows the nodes to cooperate and transmit data in a scheduled manner. Time synchronization is a middleware service common to smart sensor applications and has been widely investigated [22-24]. In this study, the TinyOS is utilized to program the time synchronization implementation.

Time synchronization is operated between the two sensor nodes. Each sensor node has its own local clock, which is not synchronized initially. By communicating with the

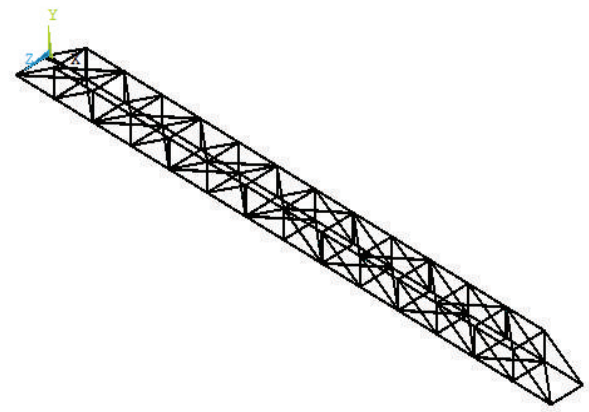

FIGURE 20: FE model.

surrounding nodes, smart sensors can assess the relative difference among their local clocks. Two tests have been carried out in this experiment, one is for $128 \mathrm{~Hz}$ sampling frequency and the other is for $64 \mathrm{~Hz}$ sampling frequency. The time synchronization results are presented in Figures 17 and 18. It can be found that the synchronization error between the two sensing units is measured to be within $100 \mu$ s which is ignorable in practice. However, it should be noted that the sampling frequency of sensor has major effect on the time synchronization error. The time synchronization error for $128 \mathrm{~Hz}$ sampling frequency is almost 5 times that of sampling frequency of $64 \mathrm{~Hz}$.

\section{Evaluation on a Real Truss Structure}

In order to validate the capability of the designed wireless sensor network for structural dynamic strain monitoring, a multipoint strain monitoring system is developed on a $3 \mathrm{D}$ truss structure. 


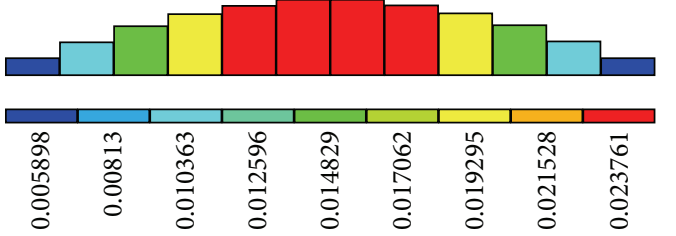

(a) First vertical mode

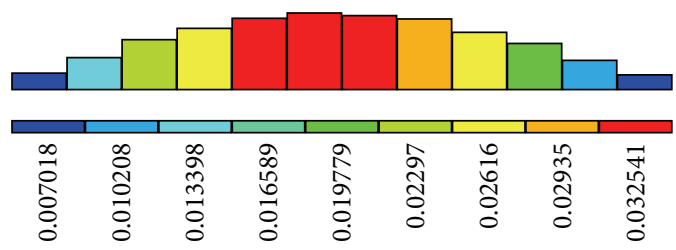

(b) First lateral mode

FIGURE 21: Strain modes identified by FE simulation.

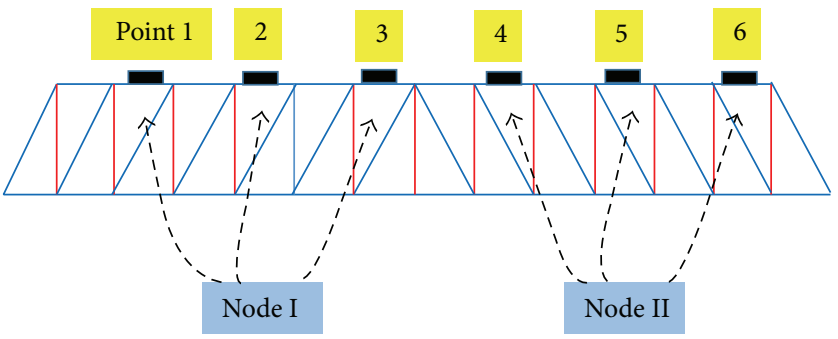

FIGURE 22: The arrangement of the measure points.

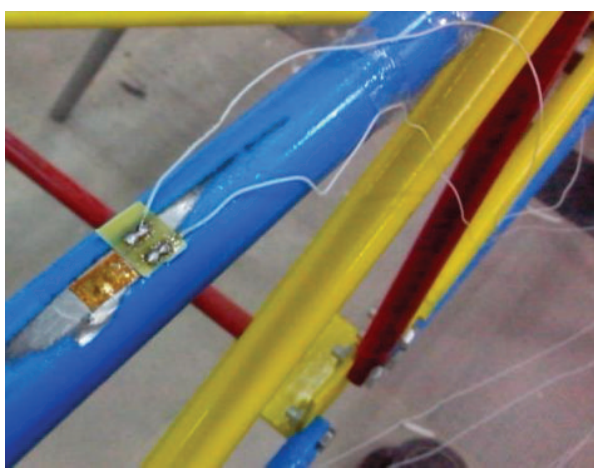

(a)

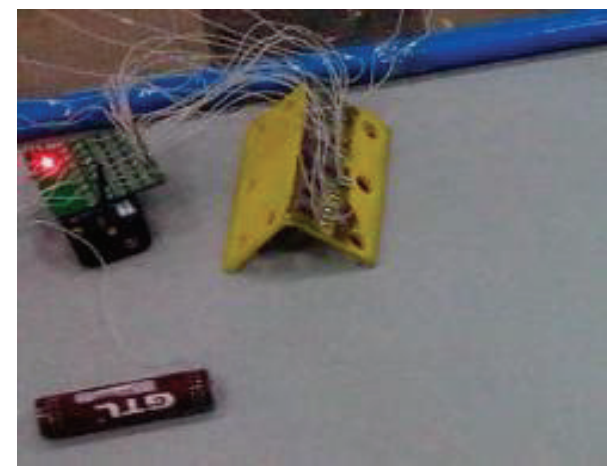

(b)

FIgURE 23: Experiment: (a) resistance strain gauge and (b) compensated strain gauge.

5.1. Experimental Truss Structure. The test structure is a steel truss with 14 bays, as shown in Figure 19. Each bay is $585 \mathrm{~mm}$ long, $490 \mathrm{~mm}$ wide, and $350 \mathrm{~mm}$ high. Totally, the steel truss has 52 longitudinal chords, 50 crosswise chords, and 54 diagonal chords. Each chord is forged with steel pipe. The chord section is hollow circular with an outer diameter of $18 \mathrm{~mm}$ and inner diameter of $12 \mathrm{~mm}$. The rods are bolted on the gusset plates which are equilateral angle steel. The structure is simply supported with movement in the longitudinal direction only.

5.2. Finite Element Analysis. Finite element (FE) simulation is performed for the test structure in order to export modal parameters and give a comparison to the following experiment results. Link element has been used to simulate all members. The mass of the gusset is distributed on all the members. The established FE model is shown in Figure 20. The FE analysis results of natural frequencies of the test structure are listed in Table 4 . From the table, we can see that the test structure has relatively high natural frequencies and many coupled vibration modes due to its large stiffness in both vertical and lateral direction. The first two strain mode shapes are shown in Figure 21. They are pure bending modes in vertical and lateral direction.

5.3. Dynamic Strain Monitoring Based on Developed WSSN. The developed wireless strain sensor nodes are attached to the truss model at 6 points of the upper chords, as shown in Figure 22. The left three measure points $(1,2$, and 3$)$ are located at even across and the right three measure points (4, 5 , and 6) are located at odd across. Leaf node I is used to acquire dynamical strain signals for the left three points and leaf node II for the right three points. Figure 23(a) shows the strain gauge attached to the chord surface. Figure 23(b) shows a leaf sensor node and the temperature compensating elements implemented on a steel angle.

5.4. Experimental Data Analysis. Figure 24 shows the time history curve and frequency spectrum of dynamical strain signals for measuring points 4,5 , and 6 , which are collected 
TABLE 4: Result of modal analysis.

\begin{tabular}{lccccc}
\hline Mode & First vertical & First lateral & Lateral and torsion & Torsion and vertical & Second vertical \\
\hline Natural frequency $(\mathrm{Hz})$ & 8.785 & 11.293 & 19.833 & 28.934 & 32.265 \\
\hline
\end{tabular}

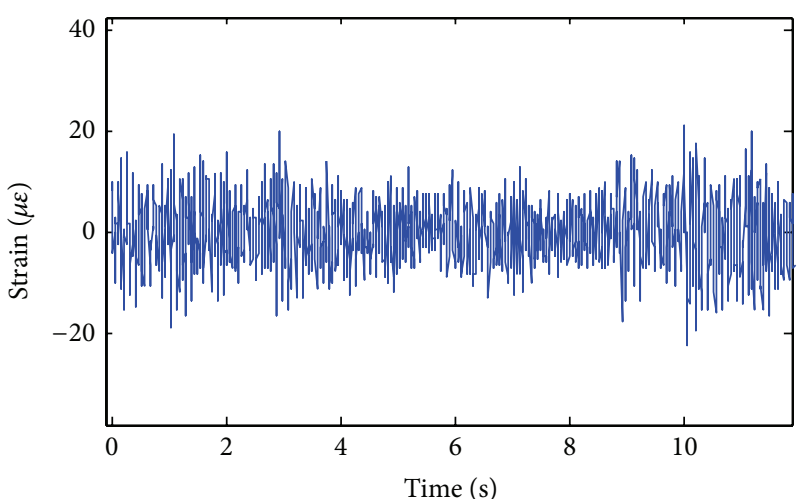

$-\mathrm{AD} 1$

(a) Strain signal of AD1

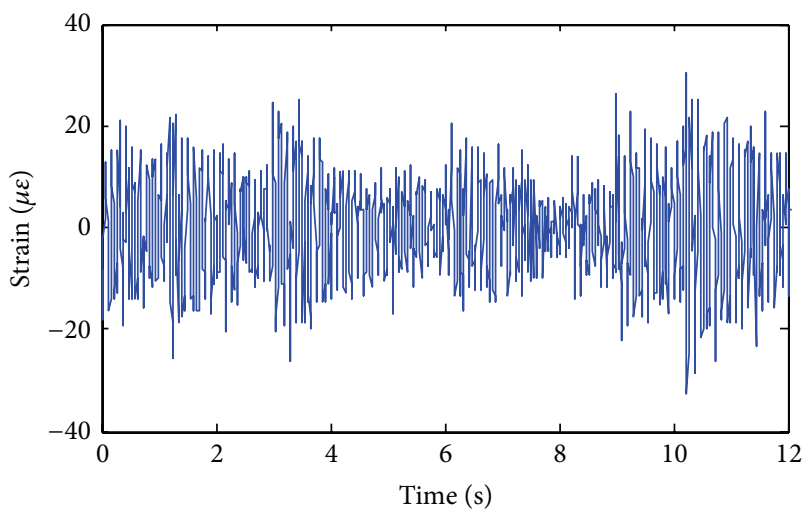

$-\mathrm{AD} 2$

(c) Strain signal of AD2

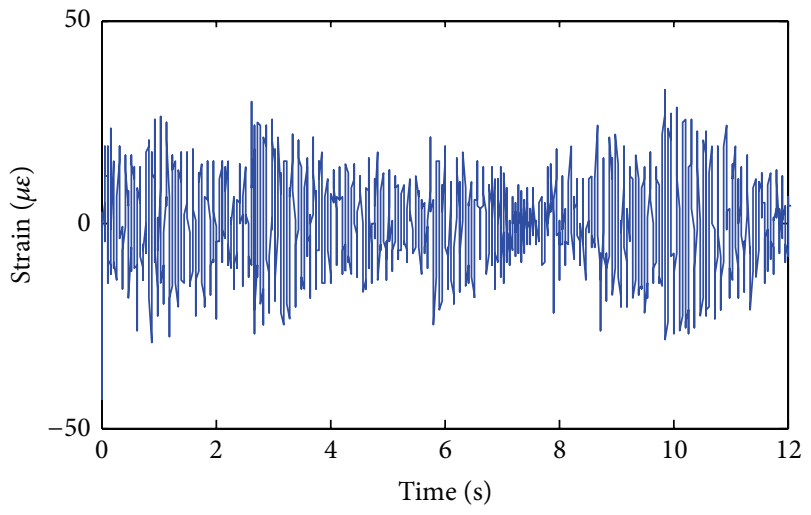

$-\mathrm{AD} 4$

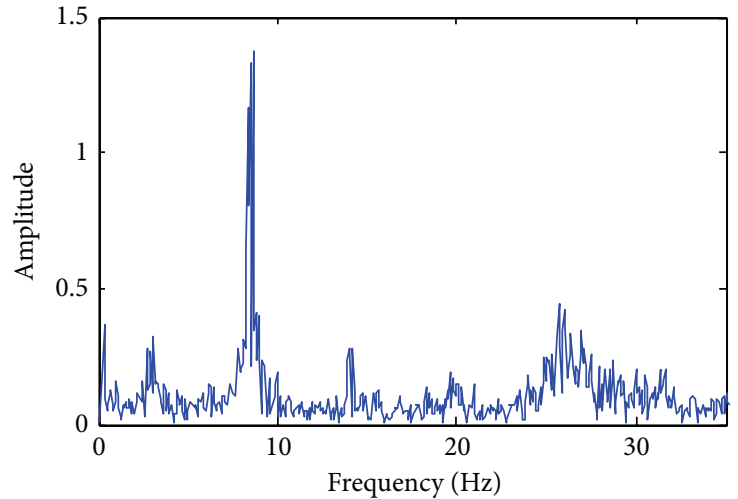

$-\mathrm{AD} 1$

(b) Frequency spectrum of AD1

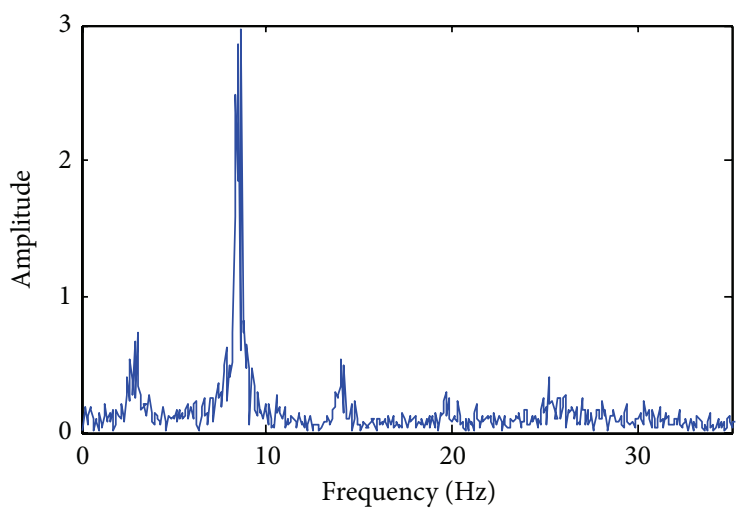

$-\mathrm{AD} 2$

(d) Frequency spectrum of AD2

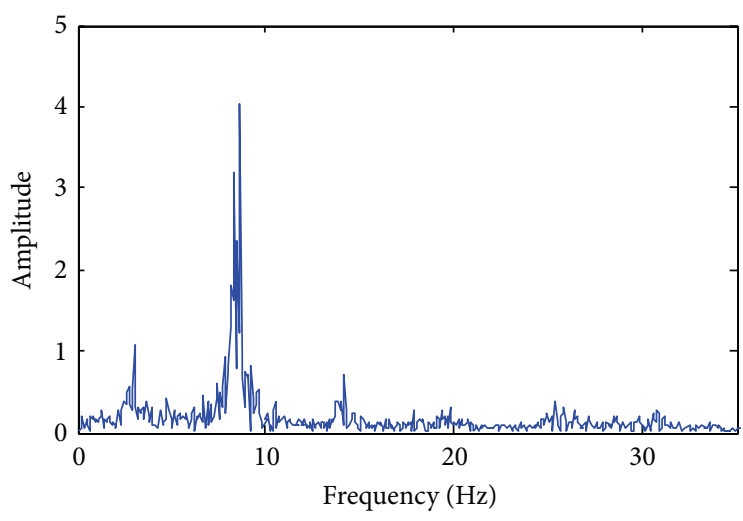

$-\mathrm{AD} 4$

(e) Strain time history of AD4

(f) Frequency spectrum of AD4

FIGURE 24: Strain signals and frequency spectrums of node II. 
TABLE 5: FDD frequency identification compared to FE modal analysis.

\begin{tabular}{lccccc}
\hline Method & 1st vertical & 1st lateral & Lateral and torsional & Vertical and torsional & 2nd vertical \\
\hline WSSN & 8.518 & 14.080 & 19.643 & 26.770 & 30.420 \\
FE & 8.785 & 11.239 & 19.833 & 28.934 & 32.365 \\
\hline
\end{tabular}

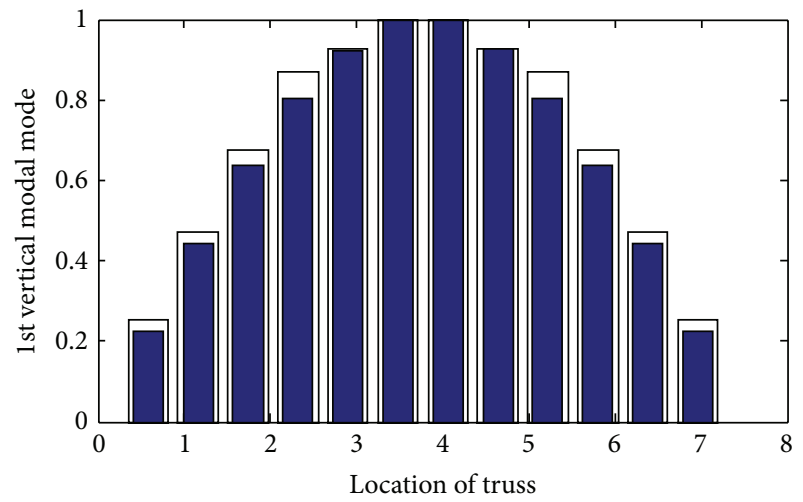

$\square$ Wireless strain sensor Finite element method

(a)

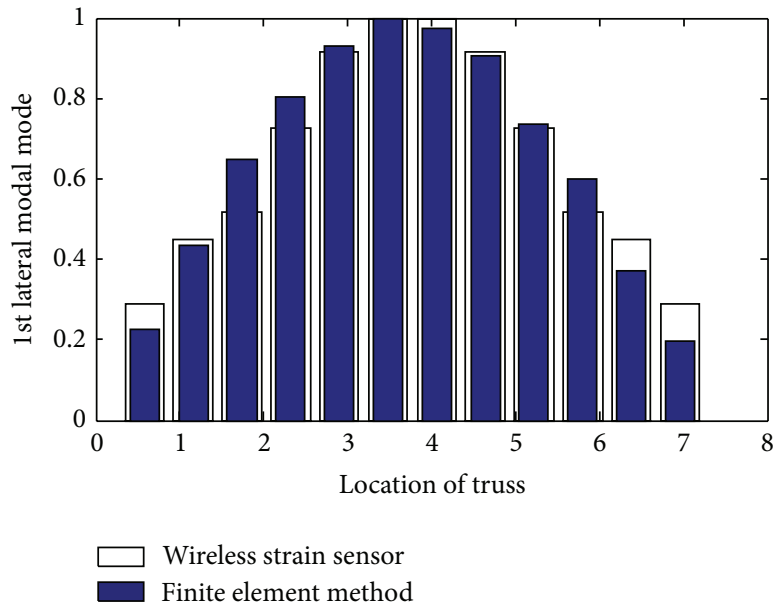

(b)

FIgURE 25: Modes identified by the WSSN: (a) 1st vertical mode and (b) 1st lateral mode.

by the $\mathrm{AD} 4, \mathrm{AD} 2$, and $\mathrm{AD} 1$ channels of node II, respectively. Node I has similar results.

Point 6 close to the end of span has the minimum vertical strain value. It contains other components such as lateral signal or reverse signal which is the properties of end bay. Point 4 locates at the middle span and it has the maximum strain value and the maximum amplitude of spectrum. From the frequency spectrum, we can see that the amplitude of the first vertical vibration mode is the highest, and, therefore, it satisfies the sensitivity of the strain property in low order vibration mode.

Considering the symmetrical characteristic of the test structure, the measuring data are analyzed using frequency domain decomposition (FDD) method to extract strain modal parameters (vibration modes and natural frequencies). Table 5 lists the natural frequencies of the test structure obtained by WSSN and FE simulation. It can be found that the identified natural frequencies are in good agreement. The fundamental natural frequency of test structure is $8.518 \mathrm{~Hz}$, which is higher than that of many real civil infrastructures.

Figures 25(a) and 25(b) show the first vertical and first lateral modal shapes of the test structure obtained from experiment, respectively. They are almost identical to the modal shapes obtained in FE simulation in Section 5.3. The experiment results demonstrate that the WSSN can accurately identify low order vibration modes, while other identified higher order vibration modes are irregular, due to the large stiffness of the test structure. This difficulty mainly comes from synchronization. When the larger sampling frequency is used, time synchronization error between two sampling nodes becomes higher, leading to a larger phase error between two measuring points. For most real civil infrastructures, their fundamental frequencies are lower than those of the test structure in this study, which indicates that the proposed WSSN could satisfy the SHM application requirements.

\section{Conclusions}

This work presents the design and characterization of a new wireless strain sensor board. The results of the characterization of the fabricated device in combination with IRIS mote show very good performance with respect to the devices' static, sensitivity, and dynamical characteristics. The experimental verification of the WSSN on a truss structure combined with FE simulation demonstrates that the developed WSSN is able to verify the natural frequencies and lower order strain mode shapes. However, difficulties are found in the identification of higher order strain modal shapes due to phase errors in time synchronization. The requirements on the time synchronization for modal analysis need to be assessed mainly from the viewpoint of mode shape phases. Despite the inaccuracy of modal identification in higher order vibration modes, the developed WSSN offers the potential of dynamic strain field monitoring of civil infrastructures, which is very important with respect to the acceptance of this new system. For future work, hardware capabilities of the wireless strain sensor node need further improvement in order to satisfy the transmission rate and bandwidth requirements for large volume deployment in real applications. 


\section{Conflict of Interests}

The authors declare that there is no conflict of interests regarding the publication of this paper.

\section{Acknowledgments}

This work is supported by National Key Technology R\&D Program (Grant no. 2014BAL05B06), Natural Science Foundation of China (Grant no. 51108129), Guangdong Major Science and Technology Plan (Grant no. 2012A080104014), Shenzhen Overseas Talents Project (Grant no. KQCX20120802140634893), and the Ministry of Education Key Laboratory of C\&PC Structures.

\section{References}

[1] V. Giurgiutiu, J. M. Redmond, D. P. Roach, and K. Rackow, "Active sensors for health monitoring of aging aerospace structures," in 7th Annual International Symposium on Smart Structures and Materials, vol. 3985 of Proceedings of SPIE, pp. 294-305, The International Society for Optical Engineering, June 2000.

[2] B. F. Spencer, "Opportunities and challenges for smart sensing technology," in Proceedings of the 1st International Conference on Structural Health Monitoring and Intelligent Infrastructure, pp. 65-72, Tokyo, Japan, 2003.

[3] J. Hill, R. Szewczyk, A. Woo, S. Hollar, D. Culler, and K. Pister, "System architecture directions for networked sensors," in Proceedings of the 9th International Conference on Architectural Support for Programming Languages and Operating Systems, pp. 93-104, Cambridge, Mass, USA, 2000.

[4] N. Kurata, B. F. Spencer, M. Ruiz-Sandoval, Y. Miyamoto, and Y. Sako, "A study on building risk monitoring using wireless sensor network MICA-Mote," in Proceedings of the 1st International Conference on Structural Health Monitoring and Intelligent Infrastructure, pp. 353-363, Tokyo, Japan, 2003.

[5] Crossbow Technology Incorporated, http://www.xbow.com.cn/.

[6] J. Paek and R. Govindan, "RCRT: rate-controlled reliable transport protocol for wireless sensor networks," ACM Transactions on Sensor Networks, vol. 7, no. 3, article 20, 2010.

[7] S. Kim, S. Pakzad, D. Culler et al., "Health monitoring of civil infrastructures using wireless sensor networks," in Proceedings of the of the 6th International Conference on Information Processing in Sensor Networks, pp. 254-263, Cambridge, Mass, USA, 2007.

[8] B. A. Sundaram, K. Ravisankar, R. Senthil, and S. Parivallal, "Wireless sensors for structural health monitoring and damage detection techniques," Current Science, vol. 104, no. 11, pp. 14961505, 2013.

[9] J. P. Lynch, Y. Wang, K. H. Law, J. H. Yi, C. G Lee, and C. B. Yun, "Validation of a large-scale wireless structure monitoring system on the Geumdang bridge," in Proceedings of the 4th International Conference on Safety and Structural Reliability (ICOSSAR '05), Rome, Italy, 2005.

[10] M. Bocca, E. I. Cosar, J. Salminen, and L. M. Eriksson, "A reconfigurable wireless sensor network for structural health monitoring," in Proceedings of the 4th International Conference on Structural Health Monitoring on Intelligent Infrastructure (SHMII '09), pp. 22-24, Zurich, Switzerland, 2009.
[11] M. Bocca, L. M. Eriksson, A. Mahmood, R. Jäntti, and J. Kullaa, "A synchronized wireless sensor network for experimental modal analysis in structural health monitoring," ComputerAided Civil and Infrastructure Engineering, vol. 26, no. 7, pp. 483-499, 2011.

[12] M. Bocca, J. Toivola, L. M. Eriksson, J. Hollmén, and H. Koivo, "Structural health monitoring in wireless sensornetworks by the embedded Goertzel algorithm," in Proceedings of the IEEE/ACM International Conference on Cyber-Physical Systems (ICCPS '11), pp. 206-214, IEEE, Chicago, Ill, USA, April 2011.

[13] J. S. Leng, D. Winter, R. A. Barnes, G. C. Mays, and G. F. Fernando, "Structural health monitoring of concrete cylinders using protected fibre optic sensors," Smart Materials and Structures, vol. 15, no. 2, pp. 302-308, 2006.

[14] H. de Backer, W. de Corte, and P. van Bogaert, "A case study on strain gauge measurements on large post-tensioned concrete beams of a railway support structure," Insight: Non-Destructive Testing and Condition Monitoring, vol. 45, no. 12, pp. 822-830, 2003.

[15] K. G. Ong and C. A. Grimes, "Tracking the harmonic response of magnetically-soft sensors for wireless temperature, stress, and corrosive monitoring," Sensors and Actuators A: Physical, vol. 101, no. 1-2, pp. 49-61, 2002.

[16] M. Shiraishi, H. Kumagai, H. Inada, Y. Okuhara, and H. Matsubara, "The SHM system using self-diagnosis material and wireless data measurement device," in Smart Structures and Materials 2005: Sensors and Smart Structures Technologies for Civil, Mechanical, and Aerospace Systems, vol. 5765 of Proceedings of SPIE, pp. 187-194, 2005.

[17] R. C. Tennyson, T. Coroy, G. Duck et al., "Fibre optic sensors in civil engineering structures," Canadian Journal of Civil Engineering, vol. 27, no. 5, pp. 880-889, 2000.

[18] J. T. DeWolf, R. G. Lauzon, and M. P. Culmo, "Monitoring bridge performance," Structural Health Monitoring, vol. 1, no. 2, pp. 129-138, 2002.

[19] E. Shehata and S. Rizkall, "Intelligent sensing for innovative bridges," Journal of Intelligent Material Systems and Structures, vol. 10, no. 4, pp. 304-313, 1999.

[20] M. J. Whelan, M. V. Gangone, and K. D. Janoyan, "Highway bridge assessment using an adaptive real-time wireless sensor network," IEEE Sensors Journal, vol. 9, no. 11, pp. 1405-1413, 2009.

[21] M. V. Gangone, M. J. Whelan, and K. D. Janoyan, "Wireless monitoring of a multispan bridge superstructure for diagnostic load testing and system identification," Computer-Aided Civil and Infrastructure Engineering, vol. 26, no. 7, pp. 560-579, 2011.

[22] S. W. Doebling, C. R. Farrar, M. B. Prime, and D. W. Shevitz, "Damage identification and health monitoring of structural and mechanical systems from changes in their vibration characteristics: a literature review," Tech. Rep. LA-13070-MS, Los Alamos National Laboratory, 1996.

[23] Y. Lei, A. S. Kiremidjian, K. K. Nair, J. P. Lynch, and K. H. Law, "Algorithms for time synchronization of wireless structural monitoring sensors," Earthquake Engineering \& Structural Dynamics, vol. 34, no. 6, pp. 555-573, 2005.

[24] Y. Wang, J. P. Lynch, and K. H. Law, "A wireless structural health monitoring system with multithreaded sensing devices: Design and validation," Structure and Infrastructure Engineering, vol. 3, no. 2, pp. 103-120, 2007. 

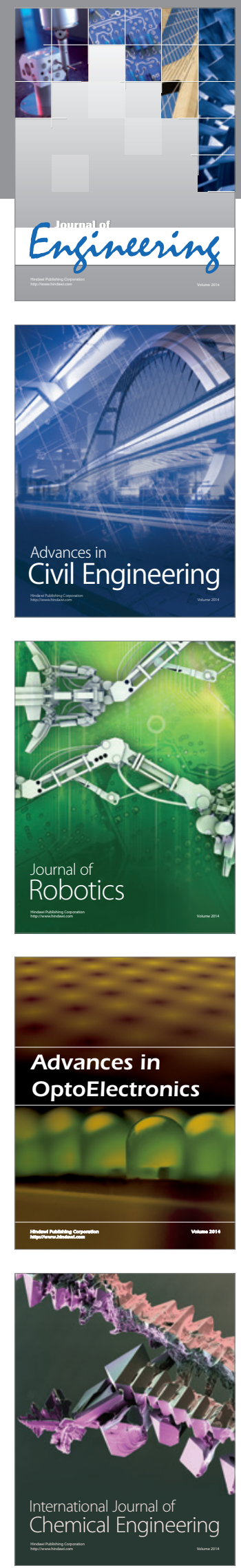

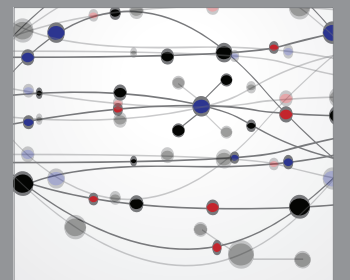

The Scientific World Journal
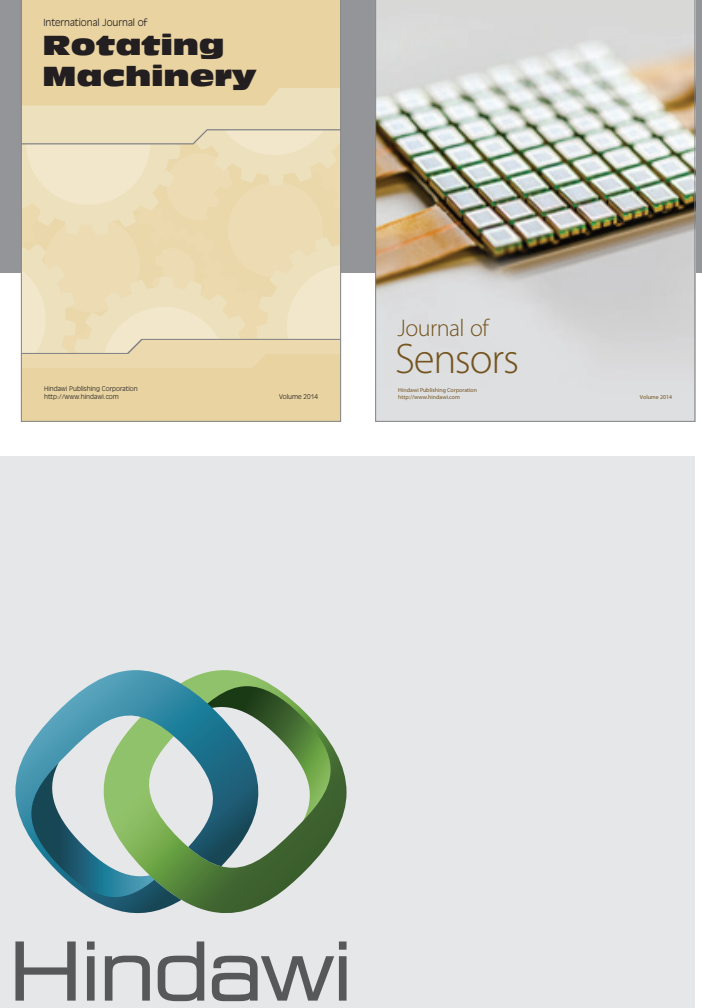

Submit your manuscripts at http://www.hindawi.com
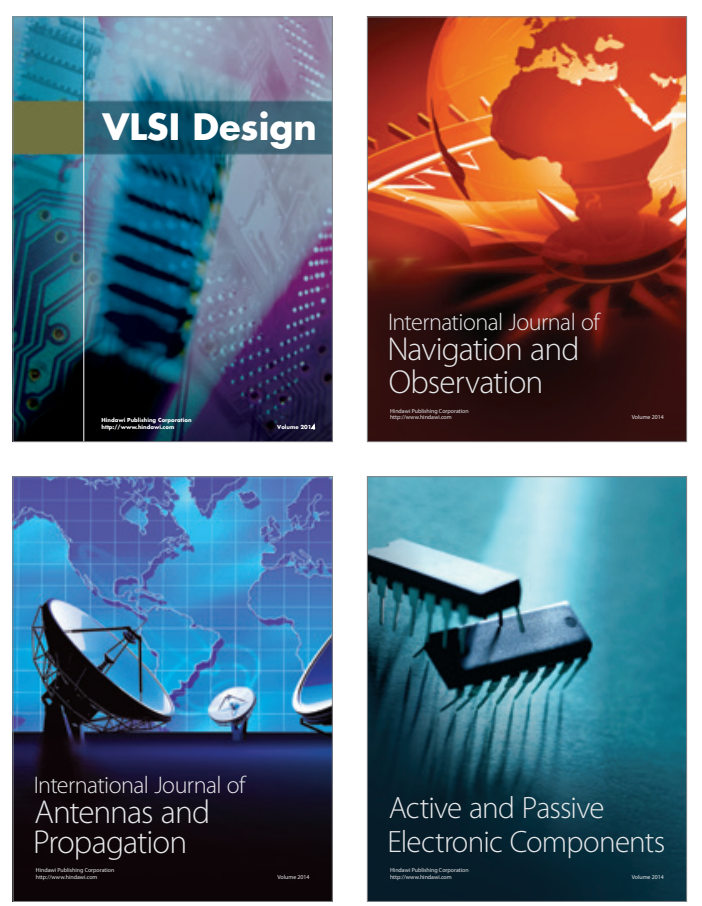
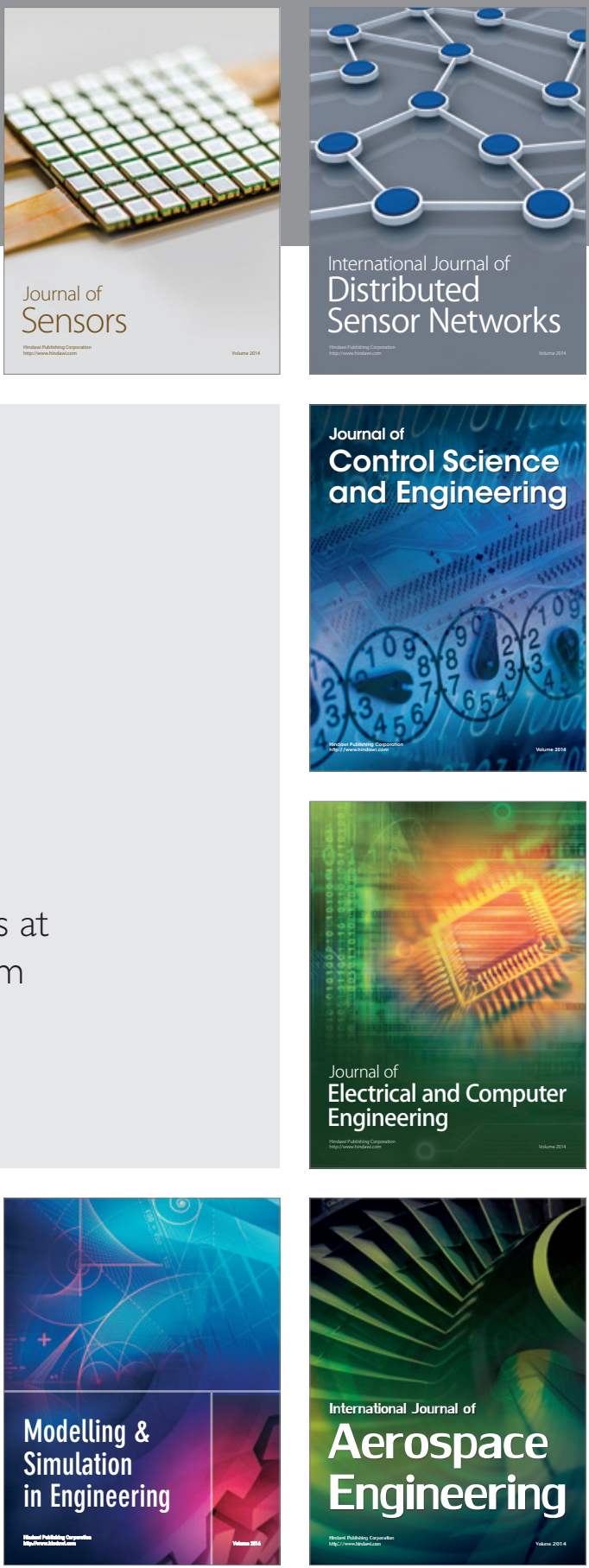

Journal of

Control Science

and Engineering
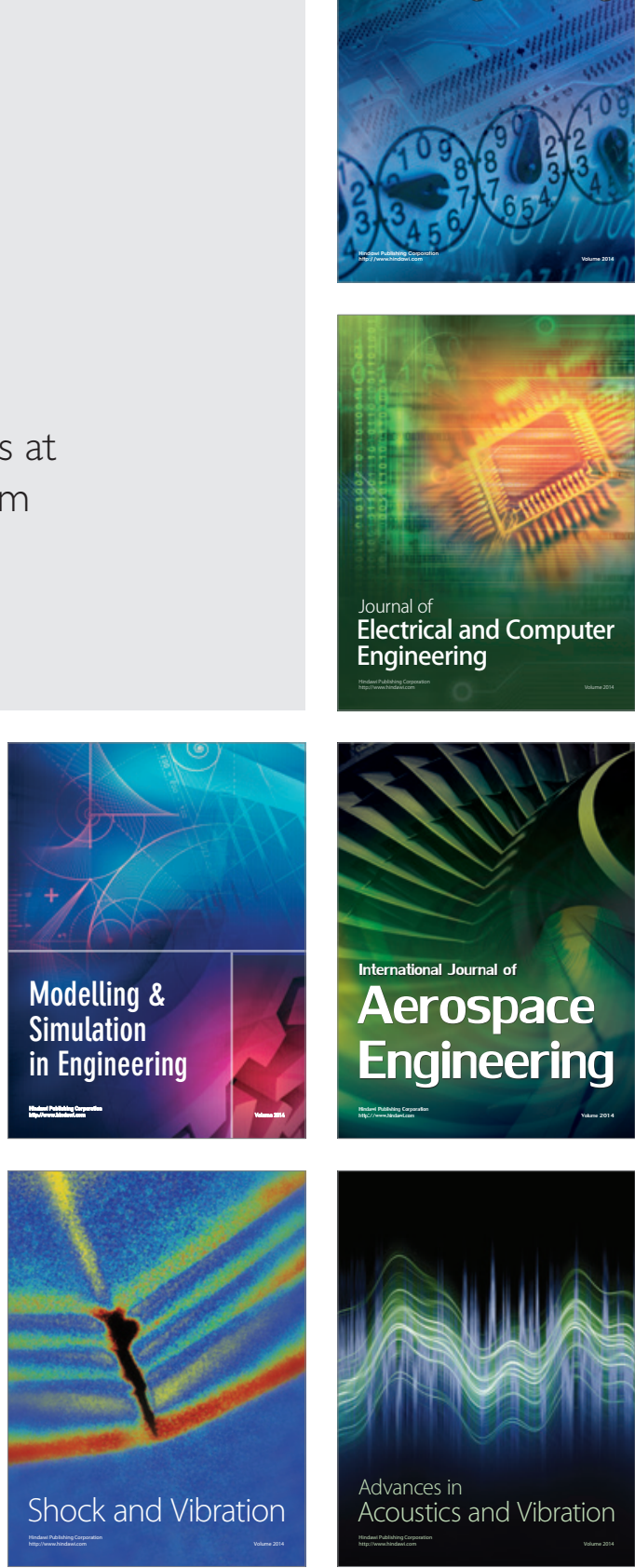